\title{
Retraction Note to: Design and surface modification of potential luminomagnetic nanocarriers for biomedical applications
}

\author{
Ranu K. Dutta $\cdot$ Prashant K. Sharma \\ Avinash C. Pandey
}

Published online: 19 August 2021

(C) Springer Nature B.V. 2021

\section{Retraction Note to: J Nanopart Res (2010) 12: 1211-1219 \\ https://doi.org/10.1007/s11051-009-9801-0}

The Editor-in-Chief has retracted this article. Concerns have been raised regarding Fig. 2a. The inset at the bottom right appears to have been previously published as Fig. 3b in Sharma et al. 2009a and Fig. 2e in Sharma et al. 2009b as representing different materials. Additionally, the article shows significant overlap with previously published articles (Sharma et al. 2009b, 2009c). The Editor-in-Chief therefore no longer has confidence in the reliability of the data reported in the article.

Ranu Dutta does not agree to this retraction. Prashant Sharma and Avinash Pandey have not responded to any correspondence from the editor/ publisher about this retraction.

\section{References}

Sharma PK, Dutta RK, Pandey AC, Layek S, Verma HC (2009a) Effect of iron doping concentration on magnetic properties of $\mathrm{ZnO}$ nanoparticles. J Magn Magn Mater 321(17):2587-2591. https://doi.org/10.1016/j.jmmm.2009. 03.043

Sharma PK, Dutta RK, Pandey AC (2009b) Doping dependent room-temperature ferromagnetism and structural properties of dilute magnetic semiconductor $\mathrm{ZnO}: \mathrm{Cu} 2+$ nanorods. J Magn Magn Mater 321(24):4001-4005. https://doi.org/10.1016/j.jmmm.2009.07.066

Sharma PK, Dutta RK, Pandey AC (2009c) Effect of nickel doping concentration on structural and magnetic properties of ultrafine diluted magnetic semiconductor $\mathrm{ZnO}$ nanoparticles. J Magn Magn Mater 321(20):3457-3461. https://doi.org/10.1016/j.jmmm.2009.06.055

Publisher's Note Springer Nature remains neutral with regard to jurisdictional claims in published maps and institutional affiliations.

The original article can be found online at https://doi.org/ 10.1007/s11051-009-9801-0.

R. K. Dutta $(\bowtie) \cdot$ P. K. Sharma · A. C. Pandey

Nanophosphor Application Centre, University of Allahabad, Allahabad 211002, India

e-mail: ranu.dutta16@gmail.com 